\title{
Discussion of Bilingual Education on Structural Mechanics- Taking Sino-UK Cooperation in Civil Engineering Project as An Example
}

\author{
Zhang Qiang ${ }^{1, a^{*}}$ and Wang Yan-lin ${ }^{1, b}$ \\ 1College of Civil Engineering, Shanghai Normal University, Shanghai 201418, China \\ a zhq@shnu.edu.cn, b353013561@qq.com
}

Key words: bilingual education; structural mechanics; teaching method

Abstract: Bilingual education on $<$ Structural Mechanics $>$ which based on the general bilingual teaching law should particularly pay attention to choose bilingual teaching content with the present situation of students. By the requirement of Sino-foreign cooperative education, the paper discusses the teaching content, teaching method, curriculum resources and practice training of $<$ Structural Mechanics >, which provides helpful reference for Sino-foreign cooperative education on classroom teaching of civil engineering subjects.

\section{Introduction}

Structural Mechanics is a basic course based on Advanced Mathematics, Theoretical Mechanics and Material Mechanics etc. However, it is also the basis of some specialized course such as Steel Structure, Reinforced Concrete Structure, Soil Mechanics and Foundation, Seismic Design of Engineering Structures. Structural Mechanics is not only applied repeatedly to the curriculum design and dissertation, but also provides basic acknowledge and calculation method. Thus, Structural Mechanics is a significant link in the whole course system.

To meet the need of society and innovate constantly is the principle for structural mechanics course. Strengthen the quality education and cultivate students' innovative ability is the goal of the structural mechanics course.

Construct Structural Mechanics course is system engineering. According to general feature of engineering colleges, the goal we chase is to improve Structural Mechanics course to foster the ability of students, cater to the information era, possess first-class standard and fit the real engineering practice.

The original teaching methodology, content and system played an important role of cultivating engineering talents. With the rapid development of science and technology, new technology, new subject and new material are constantly applied and developed. Computer technology in the background of international engineering in particular, reclaimed many new application fields which had made the original teaching methodology and content hard meet the requirement of society and knowledge structure. The main inadaptability is:

- The content of course is repeated and old.

- Lack of specific target.

- Teaching content disjointed practical project.

- Lack of stressing quality education of talent.

- Teaching methodology was backward.

- The application of modern technology was even more backward.

Recently, Chinese Civil engineering and Architecture College invested plenty of manpower and material resources that generated a series of achievements. The main outcomes are as followed:

(1) Patterns of curriculum have been divided. Structural Mechanics recombined to three parts -The Classical Structural Mechanics, Qualitative Structural Mechanics and Program Structure Mechanics on the basis of ability cultivation. These three different parts focus on manual quantitative calculation, quantitative calculation and manual qualitative calculation respectively. 
(2) The reorganization of teaching content. Teaching, research and the development of Civil Engineering are combined together; teaching and modern technology are combined together, teaching, development of students and career are combined together. The new organization of teaching content involved the features of new content, new innovation, new form and new purpose.

(3) Teaching methodologies are diversified. There are several forms like essay, study report, program issue, examination etc., to improve the quality of talent and excellent rates by the reform of teaching method.

(4) The period of material edition and revision is decreased. According to the change of educational concept and the development of modern technology, the requirement of teaching material is higher. It is hard to avoid decreasing the time of teaching material edition and revision for universities.

(5) Teaching software and the construction of item bank have functioned to the reform of teaching method and improvement of the quality. What is more, the construction of internet teaching has begun, which means that the teaching content and methodology are put to modern way and close to the international standard.

\section{the position of structural mechanics in civil engineering}

Civil engineering (Sino-UK cooperation) of which belongs to college of civil engineering of Shanghai Normal University was approved to enroll students by Chinese Ministry of Education in 2006. The program which cooperates with Edinburgh Napier University trains four-year undergraduate with the pattern of " $3+1$ " cooperation, which students who finish required credits and the requirement of graduation can get the degree of Shanghai Normal University and Edinburgh Napier University (dual degree). Civil engineering (Sino-UK cooperation) which belongs to college of civil engineering of Shanghai Normal University is the only Sino-foreign cooperation in civil engineering project that is approved by Chinese Ministry of Education in Shanghai.

Structural Mechanics is the main course of civil engineering (professional platform course), compulsory course, degree course and test course. The main contents of this course includes the reasonable constituted rules of structure, the internal force calculation and displacement of determinate structure and statically determinate structure effected by various of elements such as static, dynamic, temperature change, support moving and so on. The knowledge of this course can directly apply to virtual engineering design as well as lay a theoretical foundation of following study. By studying this course, students can transit from the professional basic course to professional course, which connects the past and future study.

\section{The choice of the contents and teaching material}

We introduce English-original teaching materials and outstanding Chinese teaching materials as assisted instruction when during our teaching ${ }^{[1-5]}$. English original teaching materials offer a good environment of English study and allow students to adapt professional English for civil engineering as quickly as possible, which will help students lay a solid foundation for following professional courses, further study abroad and foreign-related work. Nevertheless, it could be a challenge for the students who are weak in English which will lead to the tiredness of studying and hinder teaching. The problem is totally solved by Chinese assisted instruction.

\section{Discussion on teaching method}

Progressive teaching. Based on evolutionary law, we choose to teach in Chinese in the first half courses, then we combine Chinese and English in the teaching and finally the teaching pattern is based on English and supplemented by Chinese.

Inheriting and developing traditional teaching method which should meet the requirements of teaching scientifically and systematically can make sure the quality of classroom teaching. The course 
lecturers and professors should accurately teach the conceptual framework, make the focal points stand out and explain the key points and difficult points from the outside to the inside.

Upholding and improving the traditional teaching method which should pay attention to the unity of theory and practice during teaching course. The main teaching method of Structural Mechanics is course teaching. What's more, operate practice and CAI will help the course teaching. We apply modern teaching method to course which did enhance students' perception and positivity. Furthermore, it did promote students' thinking and potential thanks to the wall chat, transparencies and multimedia.

Teaching method of group discussion. Group discussion benefits the students' activity of study and fosters the spirit of teamwork. It requires the teacher to carefully pick out the contents that will be discussed. What's more, it need balance the numbers of students who has better ability of thinking, who has better presentation skill, who has better logical thinking and who has better manipulative ability in every group. After grouping, it should ask students to divide the work in the group which requires sharing the materials and the results of data collection and form the method of solving problems. Every student should prepare presentation based on their own work which may be queried by teachers. In the end, teacher gives marks to everyone according to the team report, presentation and the consequences of the answer. Cooperative teaching method reflects the idea of 'student-centered' in some way. In addition, it can make students study in practice and unite the examination.

Roundly strengthening the engineering practice in different ways. Engineering practice is an important part of finishing the basic training of an engineer which need the students combine the professional course with practice and take practice and results as target. It also is a stage of fostering the students' creative thinking. It should be roundly strengthened in different ways. It combines knowledge and practice organically which is the main way to improve the students' overall quality. What can we do is not only build innovative structural model project but also many other ways such as designing and making structural model, doing model loading experiment, fostering the ability of practice, the ability of innovation, the ability of solving problems and guiding and supporting students to take part in the structure design contest and undergraduates innovation fund project.

The structure of online-structural mechanics teaching system. It includes instructional program in Chinese and English, teaching plan, teaching video, the system of Q\&A, the system of delivering students' assignment and the system of exercise .

\section{Summary}

Teaching content has been optimized

As the reform of education system which reflected in three aspects: Scholastic Year System turns to Credit System, pattern of cultivating talent turns from narrow major, essential teaching to widen major, quality education and Education time is compressed, most of the country's universities combine or adjust the original basic course. Our civil engineering college has made several investigations to related universities and employing units in order to modify the teaching content and syllabus based on the sufficient investigation, the focus on the educational ideology and the renewal of educational ideology. After several years' practice and reform, the results almost achieved what we expected.

Teaching effect has been improved

According to the course feature of comprehensive teaching content and less credit-hour, the multimedia courseware has been improved. After finishing every teaching, the teaching content and the multimedia course ware should be evaluated, and the feedback from students should be collected to improve the teaching quality gradually.

Construct the comprehensive experimental program of Structural Mechanics

Students are fostered the practice ability, innovation ability, independent analysis ability and the ability of solving questions in the aspects of theoretical analysis and calculation method. To strengthen the understanding of the basic theory and actual engineering, construct the ability of applying modern technology skill to analysis structure by computer. 
Construct the structural model design innovation experiment

To cultivate students' practical ability, students are asked to design and make structural model, and do the model loading test. Structural design competition and innovation program are also encouraged to students.

The initiatory test book of Structural Mechanics is completed

The test book which involved the main content of class and the content of last chapter to link the knowledge is completed.

The discussion and practice in Sino-UK cooperation

The program of Civil engineering cooperates with Edinburgh Napier University. Parts of the teaching are taught by the lecturers from Edinburgh Napier University. After seven years practice, the initial purpose has been almost realized. However, there are still some aspects being improved. Especially, some students choose to go to Britain to finish the fourth year (honour year), while some still stay in China for their graduate year. How to balance the teaching content and methodology is still need to discuss.

\section{References}

[1] Song Xiuyu4, Luo Yaocheng, Fan Yuanwei. The Issues in Brand Building of Universities' Sino-Foreign Cooperative Education Projects and Reforms to deal with[J]. High Education Forum, 2015,33(4),PP.33-36.

[2] Xie Yinping. Teaching Quality Control for Chinese-foreign Partnership Programs [J]. Journal of Longyan University, 2015 , 33 ( 1 ) PP.53-58.

[3] Geng Weihua, Kan Xuedong. Present Situation of Sino-foreign Cooperation in Running Schools Development of Higher Education and Problems[J]. Journal of Shanxi Institute of Economic Management, 2015, 23(1)PP.97-112.

[4] Yin Hau, Luo Huai. Joint Education and Teaching Management Situation Analysis and Research [J]. Journal of Shanxi Coal-Mining Administrators College, 2014 , 27 ( 4 ) PP.102-104.

[5] Yu Liming, Xu Ping, Zhang Li, Chen Hui, Xiong Zhang. Exploration and practice in joint educational model [J]. Global Views, 2014 ( 5 ) PP.1-5,55. 